\title{
PENERAPAN DATA MINING UNTUK MENENTUKAN PENJUALAN SPAREPART TOYOTA DENGAN METODE K-MEANS CLUSTERING
}

\author{
Saut Parsaoran Tamba*, Felix Toknady Kesuma, Feryanto \\ Program Studi Sistem Infomasi Fakultas dan Ilmu Komputer Universitas Prima Indonesia \\ E-mail : *saut_nabasa@yahoo.co.id
}

\begin{abstract}
ABSTRAK - Semakin berkembangnya persaingan dalam dunia bisnis khususnya dalam industri penjualan sparepart mobil dan jasa serivice menuntut para pengembang untuk menemukan suatu pola yang dapat meningkatkan penjualan dan pemasaran barang di perusahaan, salah satunya adalah dengan pemanfaatan data transaksi. CV Terang Jaya merupakan perusahaan yang begerak dalam bidang Otomotif yang melayani pembelian, penjualan sparepart mobil serta memberikan service untuk berbagai merek mobil. Namun demikian kurang dalam peninjauan produk-produk apa saja yang dibutuhkan konsumen dan penyimpanan data-data yang kurang efektif. Untuk mengatasi permasalahan tersebut analisis yang digunakan yaitu penerapan Clusteringdengan menggunakan Algoritma K-Means. Clustering merupakan salah satu teknik dari salah satu fungsionalitas data mining, algoritma clustering merupakan algoritma pengelompokkan sejumlah data menjadi kelompok-kelompok data tertentu (cluster). Sehingga dengan adanya pengelompokan data ini pihak perusahaan dapat mengetahui barang paling laris, laris dan tidak laris. Sehingga barang yang ada digudang tidak menumpuk. Dari penitian ini output yang dihasilakan yaitu, barang paling laris sebanyak 15, barang yang laris sebanyak 45 dan kurang laris sebanyak 13. Dengan adanya pengolahan data yang dilakukan diharapkan dapat memberikan solusi kepada pihak perusahaan agar dapat mengetahui mana barang yang paling laris, laris dan mana barang yang tidak laris.
\end{abstract}

Kata kunci: Data Mining, K-Means, Clustering, Sparepart

\section{PENDAHULUAN}

Pada era sekarang kebutuhan masyarakat terhadap alat transportasi semakin meningkat, untuk itu masyarakat memiliki kendaraan mobil pribadi guna dalam menjalani aktivitas sehari-hari. Setiap pengguna mobil pastinya ingin kendaraanya selalau dapat berjalan dengan baik. oleh karena itu perusahaan - perusahaan yang menjual suku cadang mobil beserta dengan pelayananan atau perawatan mobil harus meningkatkan produktifitas dan efisien kerja dalam usaha.

Semakin berkembangnya persaingan dalam dunia bisnis khususnya dalam industri penjualan sparepart mobil dan jasa serivice menuntut para pengembang untuk menemukan suatu pola yang dapat meningkatkan penjualan dan pemasaran barang di perusahaan, salah satunya adalah dengan pemanfaatan data transaksi. Penggunaan sistem informasi dalam persaingan yang ketat dalam suatu perusahaan dengan perusahaan yang lain merupakan salah satu masalah yang datang dari luar perusahaan.

CV Terang Jaya merupakan perusahaan yang begerak dalam bidang Otomotif yang melayani pembelian, penjualan sparepart mobil serta memberikan service untuk berbagai merek mobil. Namun demikian CV Terang Jaya kurang dalam peninjauan produk yang dijual, produk-produk apa saja yang dibutuhkan konsumen dan penyimpanan data-data kurang efektif. Dengan demikian perlu adanya suatu sistem yang dapat mendukung perusahaan dalam mengambil keputusan secara cepat dan juga tepat. Dalam hal ini analisi yang digunakan untuk mengatasi permasalahan diatas dengan menggunaan penerapan Clustering dengan menggunakan Algoritma K-Means.

Clustering merupakan salah satu teknik dari salah satu fungsionalitas data mining, algoritma clustering merupakan algoritma pengelompokkan sejumlah data menjadi kelompok-kelompok data tertentu (cluster). Sedangkan Data mining, sering juga disebut sebagai knowledge discovery in database (KDD) adalah kegiatan yang meliputi pengumpulan, pemakaian data, historis untuk menemukan keteraturan, pola atau hubungan dalam set data berukuran besar. Sehingga dengan adanya pengelompokan data ini pihak perusahaan dapat mengetahui barang paling laris, laris dan tidak laris, sehingga barang yang ada digudang tidak menumpuk. Dengan adanya pengolahan data yang dilakukan diharapkan akan dapat memberikan solusi nyata kepada pihak perusahaan agar dapat mengetahui mana barang yang paling laris, laris dan mana barang yang tidak laris.

\section{METODE PENELITIAN}

Penelitian ini menggunakan teknik klasifikasi dengan $K$-Means untuk mengelompokkan data kategorikal hingga menghasilkan klaster yang lebih stabil. Algoritma K-means Clustering adalah suatu metode penganalisaan data atau metode data mining yang melakukan proses pemodelan tanpa supervisi (unsupervised) dan merupakan salah satu metode yang melakukan pengelompokan data dengan sistem partisi. Metode $K$-Means berusaha mengelompokkan data yang ada kedalam beberapa kelompok, dimana data dalam satu kelompok mempunyai karakteristik 
yang sama satu sama lainnya dan mempunyai karakteristik yang berbeda dengan data yang ada didalam kelompok yang lain.

Tahapan melakukan clustering atau pengelompokan dengan metode $K$-Means adalah sebagai berikut :

1. Pilih jumlah cluster $k$.

2. Inisialisasi $k$ pusat clusterini bisa dilakukan dengan berbagai cara. Namun yang paling sering dilakukan adalah dengan cara random. Pusatpusat cluster diberiduberi nilai awal dengan angka-angka random.

3. Tempatkan semua data/ objek ke cluster terdekat. Kedekatan dua objek ditentukan berdasarkan jarak kedua objek tersebut. Demikian juga kedekatan suatu data ke clustertertentu ditentukan jarak antara data dengan pusat cluster. Dalam tahap ini perlu dihitung jarak tiap data ke tiap pusat cluster. Jarak paling antara satu data dengan satu clustertertentu akan menentukan suatu data masuk dalam clustermana. Untuk menghitung jarak semua data ke setiap tiitk pusat cluster dapat menggunakan teori jarak Euclidean yang dirumuskan sebagai berikut:

$D(i, j)=\sqrt{\left(x_{1 i}-x_{1 j}\right)^{2}+\left(x_{2 i}-x_{2 j}\right)^{2}}$

dimana:

$D(i, j)=$ Jarak data ke $i$ ke pusat clusterj

$X_{k i} \quad=$ Data ke $i$ pada atribut data ke $k$

$X_{k j} \quad=$ Titik pusat ke $j$ pada atribut ke $k$

4. Hitung kembali pusat cluster dengan keanggotaan cluster yang sekarang. Pusat clusteradalah rata-rata dari semua data/ objek dalam clustertertentu. Jika dikehendaki bisa juga menggunakan median dari cluster tersebut. Jadi rata-rata (mean) bukan satu-satunya ukuran yang bisa dipakai.

5. Tugaskan lagi setiap objek memakai pusat cluster yang baru. Jika pusat cluster tidak berubah lagi maka proses clustering selesai. Atau, kembali ke langkah nomor 3 sampai pusat clustertidak berubah lagi

Proses algoritma k-means dapat seperti dijabarkan dalam flowchart berikut

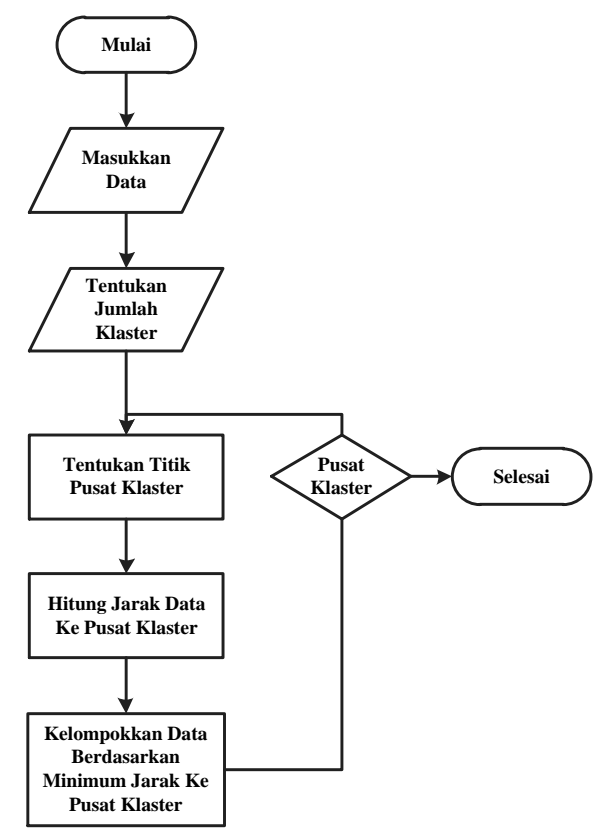

Gambar 1. Flowchart Algortima K-Means

\section{HASIL DAN PEMBAHASAN}

\subsection{Analisa Data}

Data penelitian ini diapat dari CV. Terang Jaya, dimana data yang digunakan data penjualan sebanyak 50 data. Output yang diharapkan adalah menghasilkan 3 cluster yaitu (C1) data penjualan paling laris, (C2) data penjualan yang laris, dan (C3) data penjualan kurang laris. Variabel atau atribut digunakan dalam pengelompokan data penjualan ini terdiri dari Stok Awal, dan Terjual, seperti yang terlihat pada Tabel 1.

Tabel 1. Sampel Data

\begin{tabular}{|c|l|l|c|c|}
\hline No & $\begin{array}{l}\text { Nama } \\
\text { Produk }\end{array}$ & $\begin{array}{l}\text { Tipe } \\
\text { Kendaraan }\end{array}$ & $\begin{array}{c}\text { Stok } \\
\text { Awal }\end{array}$ & Terjual \\
\hline 1 & $\begin{array}{l}\text { Bumper } \\
\text { Depan }\end{array}$ & $\begin{array}{l}\text { Fortuner } \\
2010\end{array}$ & 29 & 16 \\
\hline 2 & $\begin{array}{l}\text { Bumper } \\
\text { Depan }\end{array}$ & $\begin{array}{l}\text { Innova } \\
2010\end{array}$ & 65 & 51 \\
\hline 3 & $\begin{array}{l}\text { Bumper } \\
\text { Depan }\end{array}$ & $\begin{array}{l}\text { Avanza } \\
2012\end{array}$ & 165 & 155 \\
\hline 4 & $\begin{array}{l}\text { Bumper } \\
\text { Depan }\end{array}$ & Rush 2012 & 36 & 14 \\
\hline 5 & $\begin{array}{l}\text { Bumper } \\
\text { Belakang }\end{array}$ & $\begin{array}{l}\text { Innova } \\
2012\end{array}$ & 36 & 25 \\
\hline 6 & $\begin{array}{l}\text { Bumper } \\
\text { Belakang }\end{array}$ & $\begin{array}{l}\text { Fortuner } \\
2012\end{array}$ & 27 & 10 \\
\hline 7 & $\begin{array}{l}\text { Bumper } \\
\text { Belakang }\end{array}$ & $\begin{array}{l}\text { Avanza } \\
2010\end{array}$ & 21 & 12 \\
\hline 8 & $\begin{array}{l}\text { Kap } \\
\text { Mesin }\end{array}$ & $\begin{array}{l}\text { Avanza } \\
2012\end{array}$ & 38 & 23 \\
\hline 9 & $\begin{array}{l}\text { Kaca } \\
\text { Depan }\end{array}$ & $\begin{array}{l}\text { Avanza } \\
2010\end{array}$ & 48 & 38 \\
\hline 10 & Kaca & Fortuner, & 28 & 16 \\
\hline
\end{tabular}




\begin{tabular}{|c|c|c|c|c|}
\hline & Depan & Hilux 2012 & & \\
\hline 11 & $\begin{array}{l}\text { Kaca } \\
\text { Depan }\end{array}$ & $\begin{array}{l}\text { Rush 2010- } \\
2016\end{array}$ & 35 & 23 \\
\hline 12 & $\begin{array}{l}\text { Kaca } \\
\text { Bagasi }\end{array}$ & $\begin{array}{l}\text { Avanza } \\
2012\end{array}$ & 22 & 10 \\
\hline 13 & $\begin{array}{l}\text { Kaca } \\
\text { Bagasi }\end{array}$ & $\begin{array}{l}\text { Innova } \\
2012\end{array}$ & 20 & 13 \\
\hline 14 & $\begin{array}{l}\text { Kaca } \\
\text { Bagasi }\end{array}$ & $\begin{array}{l}\text { Fortuner } \\
2012\end{array}$ & 14 & 7 \\
\hline 15 & $\begin{array}{l}\text { Lampu } \\
\text { Besar RH }\end{array}$ & $\begin{array}{l}\text { Innova } \\
2012-2014\end{array}$ & 62 & 56 \\
\hline 16 & $\begin{array}{l}\text { Lampu } \\
\text { Besar RH }\end{array}$ & $\begin{array}{l}\text { Avanza } \\
2012 \\
\end{array}$ & 70 & 59 \\
\hline 17 & $\begin{array}{l}\text { Lampu } \\
\text { Besar RH }\end{array}$ & $\begin{array}{l}\text { G Fortuner } \\
2012\end{array}$ & 25 & 11 \\
\hline 18 & $\begin{array}{l}\text { Lampu } \\
\text { Besar RH }\end{array}$ & Rush 2012 & 12 & 4 \\
\hline 19 & $\begin{array}{l}\text { Lampu } \\
\text { Besar LH }\end{array}$ & $\begin{array}{l}\text { Innova } \\
2012-2014\end{array}$ & 28 & 16 \\
\hline 20 & $\begin{array}{l}\text { Lampu } \\
\text { Besar LH }\end{array}$ & $\begin{array}{l}\text { Avanza } \\
2012\end{array}$ & 90 & 74 \\
\hline 21 & $\begin{array}{l}\text { Lampu } \\
\text { Besar LH }\end{array}$ & $\begin{array}{l}\text { G Fortuner } \\
2012\end{array}$ & 15 & 7 \\
\hline 22 & $\begin{array}{l}\text { Lampu } \\
\text { Besar LH }\end{array}$ & Rush 2012 & 15 & 7 \\
\hline 23 & $\begin{array}{l}\text { Lampu } \\
\text { Stop RH }\end{array}$ & $\begin{array}{l}\text { Innova } \\
2012\end{array}$ & 60 & 48 \\
\hline 24 & $\begin{array}{l}\text { Lampu } \\
\text { Stop RH }\end{array}$ & $\begin{array}{l}\text { Avanza } \\
2012\end{array}$ & 70 & 59 \\
\hline 25 & $\begin{array}{l}\text { Lampu } \\
\text { Stop RH }\end{array}$ & $\begin{array}{l}\text { Fortuner } \\
2012\end{array}$ & 16 & 11 \\
\hline 26 & $\begin{array}{l}\text { Lampu } \\
\text { Stop RH }\end{array}$ & $\begin{array}{l}\text { RUSH } \\
2012 \\
\end{array}$ & 12 & 4 \\
\hline 27 & $\begin{array}{l}\text { Lampu } \\
\text { Stop LH }\end{array}$ & $\begin{array}{l}\text { Innova } \\
2012\end{array}$ & 65 & 47 \\
\hline 28 & $\begin{array}{l}\text { Lampu } \\
\text { Stop LH }\end{array}$ & $\begin{array}{l}\text { Fortuner } \\
2012\end{array}$ & 20 & 12 \\
\hline 29 & $\begin{array}{l}\text { Lampu } \\
\text { Stop LH }\end{array}$ & Rush 2012 & 21 & 10 \\
\hline 30 & $\begin{array}{l}\text { Foglamp } \\
\text { RH }\end{array}$ & $\begin{array}{l}\text { Innova } \\
2012\end{array}$ & 25 & 6 \\
\hline 31 & $\begin{array}{l}\text { Foglamp } \\
\text { LH }\end{array}$ & $\begin{array}{l}\text { Avanza } \\
2012\end{array}$ & 40 & 18 \\
\hline 32 & $\begin{array}{l}\text { Grilld } \\
\text { BUMPER }\end{array}$ & $\begin{array}{l}\text { Innova } \\
2012 \\
\end{array}$ & 50 & 27 \\
\hline 33 & Radiator & $\begin{array}{l}\text { Innova } \\
\text { Bensin } \\
2012\end{array}$ & 15 & 3 \\
\hline 34 & Radiator & $\begin{array}{l}\text { Avanza } \\
2009\end{array}$ & 50 & 43 \\
\hline 35 & Spion RH & Rush 2012 & 35 & 12 \\
\hline 36 & Spion RH & $\begin{array}{l}\text { Avanza } \\
2010\end{array}$ & 40 & 19 \\
\hline 37 & Spion RH & $\begin{array}{l}\text { Innova } \\
2005-2012\end{array}$ & 50 & 33 \\
\hline 38 & Spion LH & Rush 2012 & 18 & 4 \\
\hline
\end{tabular}

\begin{tabular}{|c|c|c|c|c|}
\hline 39 & Spion LH & $\begin{array}{l}\text { Avanza } \\
2010\end{array}$ & 29 & 15 \\
\hline 40 & Spion LH & $\begin{array}{l}\text { Innova } \\
2005-2012\end{array}$ & 35 & 20 \\
\hline 41 & $\begin{array}{l}\text { Tabung } \\
\text { Hawa }\end{array}$ & $\begin{array}{l}\text { Innova } \\
2012\end{array}$ & 15 & 1 \\
\hline 42 & $\begin{array}{l}\text { Liner FR } \\
\text { RH }\end{array}$ & $\begin{array}{l}\text { Innova } \\
2010\end{array}$ & 30 & 21 \\
\hline 43 & $\begin{array}{l}\text { Liner FR } \\
\text { RH }\end{array}$ & $\begin{array}{l}\text { Avanza } \\
2010\end{array}$ & 29 & 11 \\
\hline 44 & $\begin{array}{l}\text { Liner FR } \\
\text { RH }\end{array}$ & $\begin{array}{l}\text { Fortuner } \\
2012\end{array}$ & 20 & 7 \\
\hline 45 & $\begin{array}{l}\text { Liner FR } \\
\text { LH }\end{array}$ & $\begin{array}{l}\text { Innova } \\
2010\end{array}$ & 30 & 26 \\
\hline 46 & $\begin{array}{l}\text { Liner FR } \\
\text { LH }\end{array}$ & $\begin{array}{l}\text { Avanza } \\
2010\end{array}$ & 30 & 21 \\
\hline 47 & $\begin{array}{l}\text { Liner FR } \\
\text { LH }\end{array}$ & $\begin{array}{l}\text { Fortuner } \\
2012\end{array}$ & 17 & 4 \\
\hline 48 & $\begin{array}{l}\text { Shock FR } \\
\text { RH }\end{array}$ & Rush 2007 & 20 & 5 \\
\hline 49 & $\begin{array}{l}\text { Shock FR } \\
\text { RH }\end{array}$ & $\begin{array}{l}\text { Avanza } \\
2009\end{array}$ & 25 & 9 \\
\hline 50 & $\begin{array}{l}\text { Shock FR } \\
\text { LH }\end{array}$ & Rush 2007 & 17 & 5 \\
\hline
\end{tabular}

\subsection{Penerapan K-Means Clustering}

1. Langkah pertama menentukan jumlah cluster yang ingin dibentuk. Dalam penelitian ini cluster yang akan dibentuk adalah sebanyak 3 cluster. Kemudian tentukan titik pusat awal dari setiap cluster, dimana pusat awal ditentukan secara acak/random sebagai berikut.

Table 2. Titik Pusat Awal Cluster

\begin{tabular}{|c|c|c|}
\hline Cluster & Stok Awal & Terjual \\
\hline cluster 1 & 2 & 65 \\
\hline Cluster2 & 5 & 6 \\
\hline Cluster3 & 11 & 19 \\
\hline
\end{tabular}

2. Tempatkan semua data/ objek ke cluster terdekat dan Hitung jarak dari data ke-1 terhadap pusat cluster

$$
\begin{aligned}
\text { Cluster } 1 & =\sqrt{(65-29)^{2}+(51-16)^{2}} \\
& =1.261 \\
\text { Cluster } 2 & =\sqrt{(16-29)^{2}+(11-16)^{2}} \\
& =38 \\
\text { Cluster } 3 & =\sqrt{(35-29)^{2}+(20-16)^{2}} \\
& =22
\end{aligned}
$$

Jarak dari data ke-2 terhadap pusat cluster

$$
\begin{aligned}
\text { Cluster } 1 & =\sqrt{(65-65)^{2}+51} \\
& =0 \\
\text { Cluster 2 } & =\sqrt{(16-65)^{2}+(11-51)^{2}} \\
& =1.649
\end{aligned}
$$




$$
\begin{aligned}
\text { Cluster } 3 & =\sqrt{(35-65)^{2}+51} \\
& =991
\end{aligned}
$$

Berdasarkan hasil perhitungan jarak dari data ke1 terhadap pusat cluster di atas dapat disimpulkan bahwa jarak data pertama yang paling dekat adalah dengan cluster 3 . Hasil perhitungan selengkapnya untuk 50 data produk dapat di lihat pada tabel 3.

Tabel 3. Hasil Perhitungan Setiap Data Pada Iterasi 1

\begin{tabular}{|c|c|c|c|c|c|}
\hline \multicolumn{3}{|c|}{ Jarak Ke } & \multicolumn{3}{c|}{ Jarak Terdekat } \\
\hline Ke Cluster \\
\hline C1 & $\mathbf{C 2}$ & $\mathbf{C 3}$ & $\mathbf{C 1}$ & $\mathbf{C 2}$ & $\mathbf{C 3}$ \\
\hline 1.261 & 38 & 22 & 0 & 0 & 1 \\
\hline- & 1.649 & 991 & 1 & 0 & 0 \\
\hline 10.916 & 20.885 & 18.355 & 1 & 0 & 0 \\
\hline 1.398 & 29 & 37 & 0 & 1 & 0 \\
\hline 705 & 216 & 26 & 0 & 0 & 1 \\
\hline 1.719 & 12 & 108 & 0 & 1 & 0 \\
\hline 1.565 & 6 & 78 & 0 & 1 & 0 \\
\hline 811 & 166 & 12 & 0 & 0 & 1 \\
\hline 186 & 761 & 337 & 1 & 0 & 0 \\
\hline 1.262 & 37 & 23 & 0 & 0 & 1 \\
\hline 814 & 163 & 9 & 0 & 0 & 1 \\
\hline 1.724 & 7 & 113 & 0 & 1 & 0 \\
\hline 1.489 & 8 & 64 & 0 & 1 & 0 \\
\hline 1.987 & 18 & 190 & 0 & 1 & 0 \\
\hline 28 & 2.071 & 1.323 & 1 & 0 & 0 \\
\hline 69 & 2.358 & 1.556 & 1 & 0 & 0 \\
\hline 1.640 & 9 & 91 & 0 & 1 & 0 \\
\hline 2.262 & 53 & 279 & 0 & 1 & 0 \\
\hline 1.262 & 37 & 23 & 0 & 0 & 1 \\
\hline 554 & 4.043 & 2.971 & 1 & 0 & 0 \\
\hline 1.986 & 17 & 189 & 0 & 1 & 0 \\
\hline 1.986 & 17 & 189 & 0 & 1 & 0 \\
\hline 14 & 1.413 & 809 & 1 & 0 & 0 \\
\hline 69 & 2.358 & 1.556 & 1 & 0 & 0 \\
\hline 1.649 & - & 100 & 0 & 1 & 0 \\
\hline 2.262 & 53 & 279 & 0 & 1 & 0 \\
\hline 16 & 1.345 & 759 & 1 & 0 & 0 \\
\hline 1.566 & 5 & 79 & 0 & 1 & 0 \\
\hline 1.725 & 6 & 114 & 0 & 1 & 0 \\
\hline 2.065 & 34 & 206 & 0 & 1 & 0 \\
\hline 1.114 & 73 & 9 & 0 & 0 & 1 \\
\hline
\end{tabular}

\begin{tabular}{|c|c|c|c|c|c|}
\hline 591 & 290 & 64 & 0 & 0 & 1 \\
\hline 2.354 & 65 & 309 & 0 & 1 & 0 \\
\hline 79 & 1.058 & 544 & 1 & 0 & 0 \\
\hline 1.551 & 20 & 64 & 0 & 1 & 0 \\
\hline 1.049 & 88 & 6 & 0 & 0 & 1 \\
\hline 339 & 518 & 184 & 0 & 0 & 1 \\
\hline 2.256 & 51 & 273 & 0 & 1 & 0 \\
\hline 1.332 & 29 & 31 & 0 & 1 & 0 \\
\hline 991 & 100 & - & 0 & 0 & 1 \\
\hline 2.550 & 101 & 381 & 0 & 1 & 0 \\
\hline 935 & 114 & 6 & 0 & 0 & 1 \\
\hline 1.636 & 13 & 87 & 0 & 1 & 0 \\
\hline 1.981 & 20 & 184 & 0 & 1 & 0 \\
\hline 660 & 239 & 41 & 0 & 0 & 1 \\
\hline 935 & 114 & 6 & 0 & 0 & 1 \\
\hline 2.257 & 50 & 274 & 0 & 1 & 0 \\
\hline 2.161 & 40 & 240 & 0 & 1 & 0 \\
\hline 1.804 & 13 & 131 & 0 & 1 & 0 \\
\hline 2.164 & 37 & 243 & 0 & 1 & 0 \\
\hline
\end{tabular}

3. Setelah semua data ditempat ke dalam cluster yang terdekat, kemudian hitung kembali pusat cluster yang baru berdasarkan rata-rata angggota yang ada pada cluster tersebut.

Pembangkitan ulang centroidbaru dihitung dengan rumus sebagai berikut

$$
C=\frac{\sum m}{n}
$$

Keterangan :

$\mathrm{C}=$ centroiddata

$\mathrm{m}=$ anggota data yang termasuk kedalam centroidtertentu

$\mathrm{n}=$ jumlah data yang menjadi anggota centroidtertentu.

Berdasarkan Tabel3, titik pusat cluster baruuntuk parameter Stok Awal memiliki 10 anggota.:

$$
\begin{gathered}
\mathrm{C} 1=(0+10.916+186+28+69+554+ \\
14+69+16+79) / 10=74.50
\end{gathered}
$$

ClusterKedua (C2) memiliki 26 anggota $\mathrm{C} 2=(1.398+1.719+1.565+1.724+$ $1.489+1.987+1.64+2.262+1.986$ $+1.986+1.649+2.262+1.566+$ $1.725+2.065+2.354+1.551+2.256$ $+1.332+2.55+1.636+1.981+$ 


\section{$2.257+2.161+1.804+2.164) / 26=$ 20.81}

ClusterKetiga (C3) memiliki 14 anggota $\mathrm{C} 3=(1.261+705+811+1.262+814+$ $1.262+1.114+591+1.049+339+$ $991+935+660+935) / 14=35.64$

Ulangi perhitungan clusterbaru untuk paramater Terjual,sehingga hasil perhitungan diperoleh titik pusat baru dari setiap cluster dibawah ini.

Table 4. Titik Pusat Baru Cluster

\begin{tabular}{|c|c|c|}
\hline Cluster & Stok Awal & Terjual \\
\hline cluster 1 & 74.50 & 63 \\
\hline Cluster2 & 20.81 & 8.23 \\
\hline Cluster3 & 35.64 & 21.71 \\
\hline
\end{tabular}

4. Setelah didapatkan titik pusat yang baru dari setiap cluster, lakukan kembali dari langkah ketiga hingga titik pusat dari setiap clustertidak berubah lagi dan tidak ada lagi data yang berpindah dari satu cluster ke clusteryang lain.

\subsection{Hasil}

Berdasarkan hasil pengelompokan dari seluruh data menggunakan metode k-means clustering, didapatkan hasil akhir pengelompokan hingga iterasi ke-5, dimana titik pusat tidak lagi berubah dan tidak ada data yang berpindah antar cluster. Hasil cluster yang terbentuk dari setiap data tersebut dapat dilihat pada tabel 4.

Tabel 5. Hasil Akhir Pengelompokkan

\begin{tabular}{|c|c|}
\hline $\begin{array}{l}\text { Nama } \\
\text { Cluster }\end{array}$ & Data Barang \\
\hline Cluster 1 & $\begin{array}{c}9,10,11,12,13,14,18,27 \\
28,29,30,31,32,34,35,36 \\
45,46,50\end{array}$ \\
\hline Cluster 2 & $\begin{array}{c}1,2,3,4,5,6,7,8,16,21,22 \\
23,33,40,47,51,55,56,57 \\
58,59,60\end{array}$ \\
\hline Cluster 3 & $\begin{array}{c}15,17,19,20,24,25,26,37 \\
38,39,41,42,43,44,48,49 \\
52,53,54\end{array}$ \\
\hline
\end{tabular}

Berdasarkan hasil dari cluster yang terbentuk pada tabel 4 dapat dilihat bahwa hasil pengelompokkan dari cluster diatas seperti terlihat pada dibawah ini.

$\begin{array}{lll}\text { Nama Cluster } & & \\ \text { Barang paling laris }(\mathrm{C} 1) & =8 & \text { barang } \\ \text { Barang yang laris }(\mathrm{C} 2) & =26 & \text { barang } \\ \text { Barang kurang laris }(\mathrm{C} 3) & =16 & \text { barang }\end{array}$

\section{PENUTUP}

\subsection{Kesimpulan}

1. Dengan adanya pengelompokan data ini, pihak perusahaan dapat mengetahui barang paling laris, laris dan tidak laris. Sehingga barang yang ada digudang tidak menumpuk.

2. Dari penelitian ini output yang dihasilkan yaitu, barang paling laris sebanyak 8 , barang yang laris sebanyak 26 dan kurang laris sebanyak 16.

3. Dengan adanya pengolahan data yang dilakukan diharapkan dapat memberikan solusi kepada pihak perusahaan agar dapat mengetahui mana barang yang paling laris, laris dan mana barang yang tidak laris.

\subsection{Saran}

1. Untuk penelitian lebih lanjut dapat menambah parameter atau variabel lain untuk proses clustering.

2. Untuk penelitian berikutnya data yang digunakan lebih banyak lagi agar menghasilkan data yang akurat.

3. Pada penelitian selanjutnya dapat dilanjutkan dengan metode lain untuk pengelompokkan atau klasifikasi data.

\section{DAFTAR PUSTAKA}

[1] Zainul ArasZ, Sarjono,"Analisis Data Mining Untuk Menentukan Kelompok Prioritas Penerima Bantuan Bedah Rumah Menggunakan Metode Clustering K-Means Vol 1 No. 2, pp 159-170, 2016.

[2] Fina Nasari, Surya Darma, "Penerapan KMeans Clustering Pada Data Penerimaan Mahasiswa Baru”, 2015.

[3] Aldi Nurzahputra, Much Aziz Muslim, Miranita Khusniati,"Penerapan Algoritma K-Means Untuk ClusteringPenilaian Dosen Berdasarkan Indeks Kepuasan Mahasiswa",Vol. 16, No. 1, pp17-24,2017.

[4] Totok Suprawoto, "Klasifikasi Data Mahasiswa Menggunakan Metode K-Means Untuk Menunjang Pemilihan Strategi Pemasaran" Vol. 1, No. 1, pp 12-16,2016.

[5] Khairul Ummi, "Analisa Data Mining Dalam Penjualan Sparepart Mobil Dengan Menggunakan Metode Algoritma Apriori" Vol.8 No.3 pp 155-164,2015.

[6] Eva Rianti, "Data Mining Dalam Menentukan Penjualan Kacamata Pada Optik Zal Laris Dan Tidak Laris Menggunakan Metode Clustering" Vol. 4, No. 2, pp 267-283,2017.

[7] EJohan Oscar Ong, "Implementasi Algoritma K-Means ClusteringUntuk Menentukan Strategi Marketing President University" Vol. 12, No. 1,2013. 
[8] Gunawan Abdillah, Firman Ananda Putra, Faiza Renaldi, "Penerapan Data Mining Pemakaian Air Pelanggan Untuk Menentukan Klasifikasi Potensi Pemakaian Air Pelanggan BaruDi Pdam Tirta Raharja Menggunakan Algoritma K-Means",2016.

[9] Oyelade, O. J, Oladipupo, O. O, Obagbuwa, I. C, "Application of K-Means Clustering Algorithm for Prediction of Students' Academic Performance",Vol. 7, No. 1, pp 292-295, 2010.

[10] Unnati R. Raval, Chaita Jani, "Implementing \& Improvisation ofK-means Clustering Algorithm",Vol. 5, Issue. 5, pp 191203,2016. 